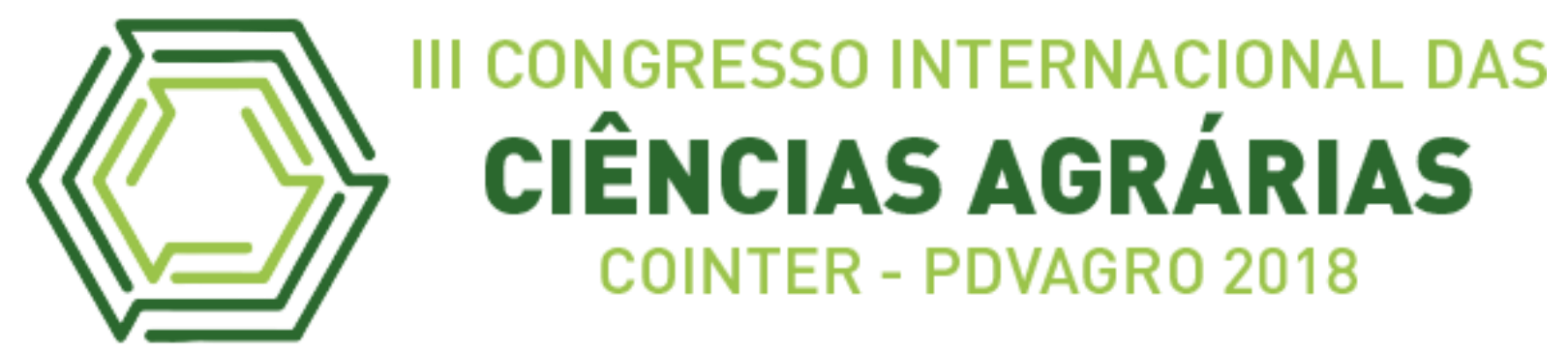

\title{
CARACTERIZAÇÃO HISTOQUÍMICA DE ANDIROBA (CARAPA GUIANENSIS AUBL.), PARA FINS FITOTERÁPICOS.
}

\section{HISTOCHEMICAL CHARACTERIZATION OF ANDIROBA (CARAPA GUIANENSIS AUBL.), FOR PHYTOTHERAPETIC PURPOSES.}

\author{
Apresentação: Pôster
}

Jéssica Rayssa Reis da $\operatorname{Costa}^{1}$; Larissa Lourenço de Oliveira ${ }^{2}$; Carina Chagas Madeira de Souza ${ }^{3}$; Joyce dos Santos Saraiva ${ }^{4}$; Manoel Euclides do Nascimento ${ }^{5}$

\section{DOI: https://doi.org/10.31692/2526-7701.IIICOINTERPDVAGRO.2018.00373}

\section{Introdução}

A andiroba (Carapa guianensis Aubl.) é uma espécie que apresenta grandes benefícios às populações da Amazônia, devido a sua grande utilidade na indústria madeireira, seu valor ecológico e propriedades medicinais do óleo extraído das suas sementes. Dentre outras propriedades, o óleo de andiroba serve como anti-inflamatório.

Nativa da Amazônia e pertencente a família Meliaceae, a Árvore de andiroba possui grande porte, chegando a atingir 30 metros de altura. A casca é grossa e tem sabor amargo é utilizada na marcenaria, na carpintaria e na medicina popular.

Segundo Boufleuer (2004) o óleo extraído das sementes é composto por consideráveis concentrações de oleína, palmitina e glicerina, que são apontados como responsáveis pela ação farmacológica da espécie. Existe interesse na extração e processamento do óleo de andiroba e beneficiamento de seus derivados como ácidos graxos, esteróis, pigmentos carotenóides e antioxidantes, uma vez que são matérias primas de extrema importância para a indústria farmacêutica, cosmética, de lubrificantes e tintas, dentre outras (CUNHA, 2002; SHANLEY, 2005). O presente trabalho baseou-se em observações morfológicas e anatômicas do exsudato por elas produzido, avaliado por meio de análises histoquímicas.

\footnotetext{
${ }^{1}$ Agronomia, Universidade Federal Rural da Amazônia, rayssacostaaa@gmail.com

${ }^{2}$ Agronomia, Universidade Federal Rural da Amazônia, lourencolarissa50@gmail.com

${ }^{3}$ Agronomia, Universidade Federal Rural da Amazônia, carina.madeira@live.com

${ }^{4}$ Agronomia. Universidade Federal Rural da Amazônia, Joyce.saraiva77@gmail.com

${ }^{5}$ Doutor em Agronomia/Fitotecnia, Universidade Federal Rural da Amazônia, manoel.nascimento@ufra.edu.br
} 


\section{Fundamentação Teórica}

Por conta da utilização medicinal da andiroba no uso popular, resolve-se estudar as folhas através de testes histoquímicos desta, devido a poucos estudos na literatura sobre a espécie.

\section{Metodologia}

As análises foram realizadas no laboratório de botânica da Universidade Federal Rural da Amazônia, a partir de material retirado de uma andirobeira do instituto de ciências agrárias (ICA) na própria universidade, no qual foi realizada a análise anatômica da espécie Carapa guianensis Abul, e identificadas às estruturas e características celulares da espécie através de cortes transversais da região do pecíolo e mesófilo.

Para a análise microscópica do material botânico foram realizados cortes histológicos, feitos à mão livre, utilizando lâminas e colocados em placas de petri contendo água e em seguida, transferidos com a ajuda de um pincel de número zero, para lâminas identificadas. Antes de iniciar os testes com os reagentes, o material foi colocado em hipoclorito de sódio, a fim de clarear o material, após o tempo de clareamento o material foi lavado em água destilada para retirada do excesso de hipoclorito de sódio. As mesmas foram preparadas de acordo com os testes a serem realizados, seguindo as técnicas laboratoriais recomendadas pela Universidade Federal do Pará em parceria com o Museu Emílio Goeldi. Os testes realizados foram o de Lugol (Johansen 1940) para os polissacarídeos, onde aplicou-se o reagente por 10 minutos, após isso, lavou-se em água destilada rapidamente. O teste de Azul de Toluidina (O’Brien et al. 1964) para lignina, o qual foi aplicado o reagente por 3 minutos e após isso, o mesmo foi lavado com água da torneira por aproximadamente 1 minutos. O teste para taninos (Mace \& Howell 1974) foi aplicada uma gota de ácido clorídrico 9\% e uma gota de vanilina clorídrica .

Após os procedimentos de preparação das lâminas, as mesmas foram para análise e identificação das estruturas no microscópio da marca OLYMPUS, onde foram capturadas as imagens por câmera fotográfica.

\section{Resultados e Discussões}

A figura 1 mostra que o teste foi positivo para a presença de amido no pecíolo de Carapa guianensis, localizado na endoderme amerígena, contornando a bainha de fibras em 
volta dos feixes vasculares. $\mathrm{Na}$ imagem mais aproximada da região é possível visualizar pontos escuros que apontam a presenta de amido.

Figura1. Corte transversal da região do pecíolo com teste de Lugol. À direita imagem aproximada. Fonte: Própria

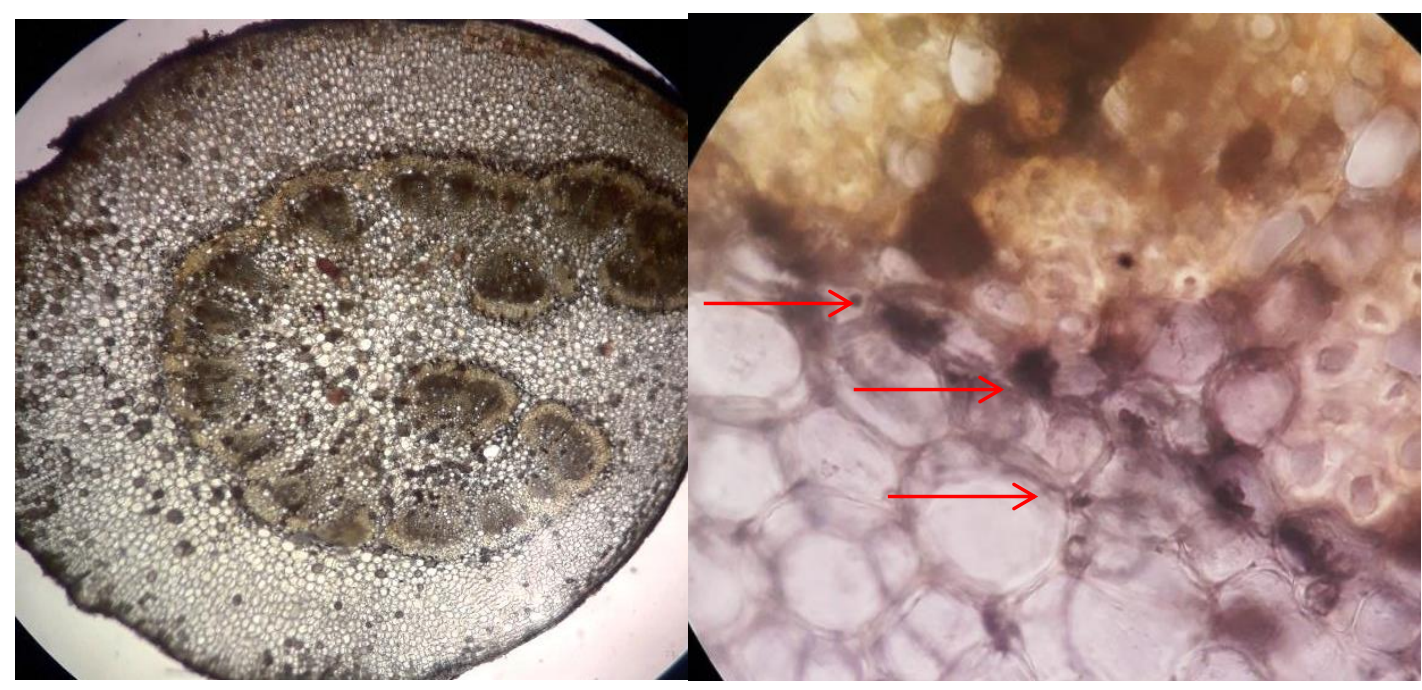

Há regiões bem escuras na imagem (figura 3) que sugerem presença de amidona nervura central da folha. Foi possível visualizar uma estrutura secretora, que pode ser vulgarmente chamada de bolsões de óleo, semelhante ao encontrado por Silva et. al, 2017 e que pode ser observada pelo destaque vermelho na imagem.

Figura 3. Região da nervura central com teste do LUGOL. Fonte: Própria

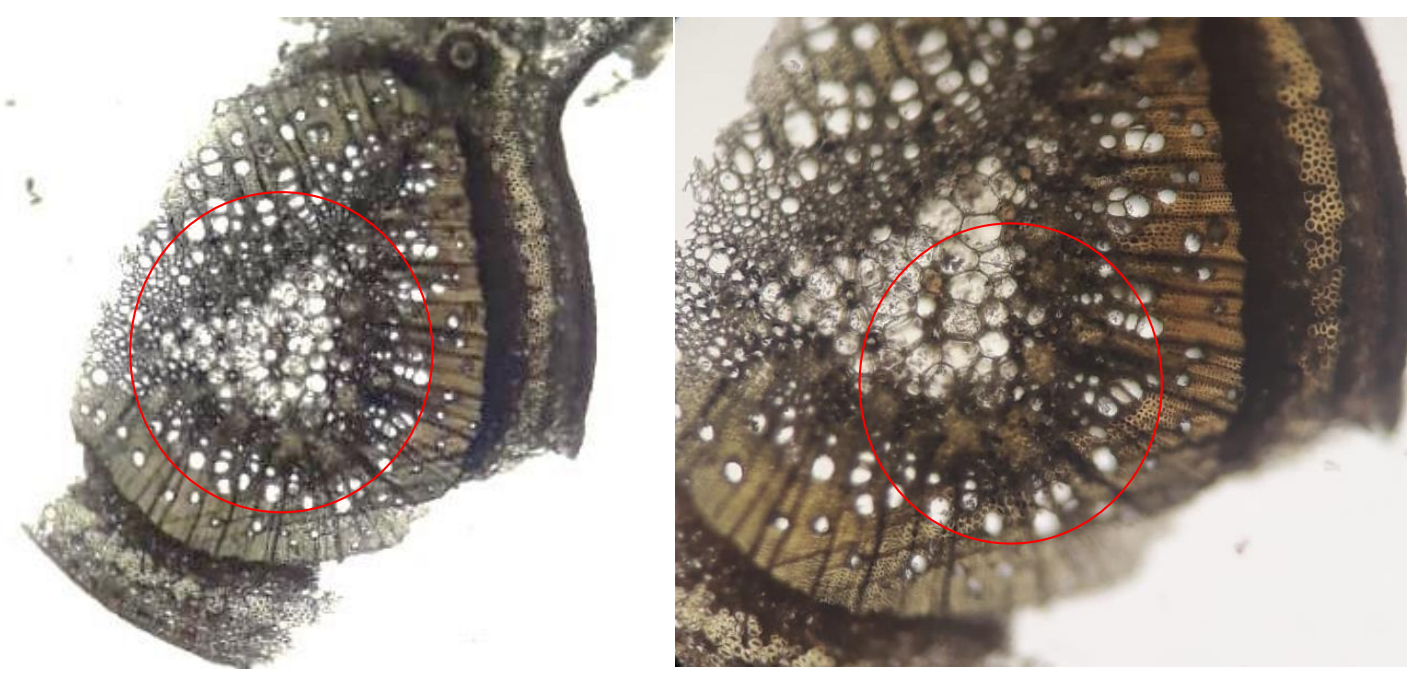


Figura 4. Região da nervura central com teste de azul de toluidina. Fonte: Própria.

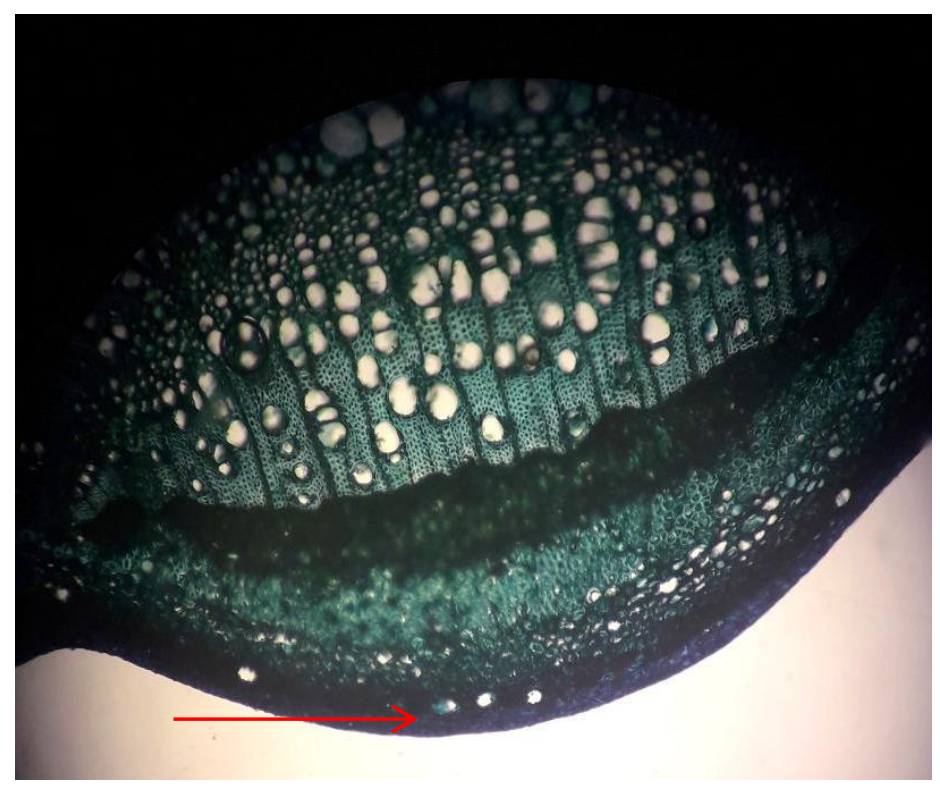

Na figura 4 é possível confirmar o teste positivo para presença de lignina na região da epiderme e região do colênquima.

Figura 5. Região aproximada do pecíolo com teste de ácido clorídrico e vanilina. Fonte: Própria

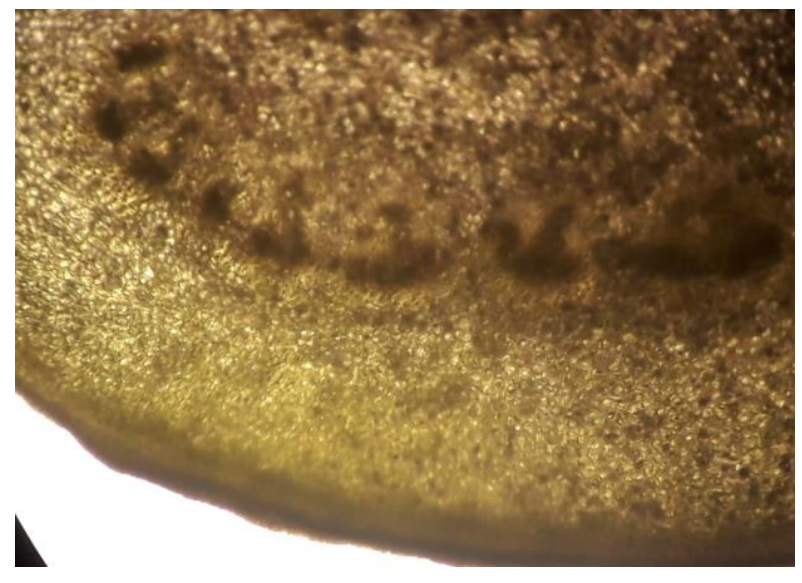

$\mathrm{Na}$ figura 5 podemos observar que o teste para taninos deu positivo na parte do mesófilo, ficando visível sua presença na região externa do xilema. Já na figura 6 , a presença 
de tanino ficou evidente abaixo da epiderme, apesar do teste ser para taninos, foi possível notar a presença de lignina em volta dos feixes vasculares no esclerênquima e parênquima axial.

Figura 6. Região aproximada da nervura centralcom teste de ácido clorídrico e vanilina. Fonte: Própria

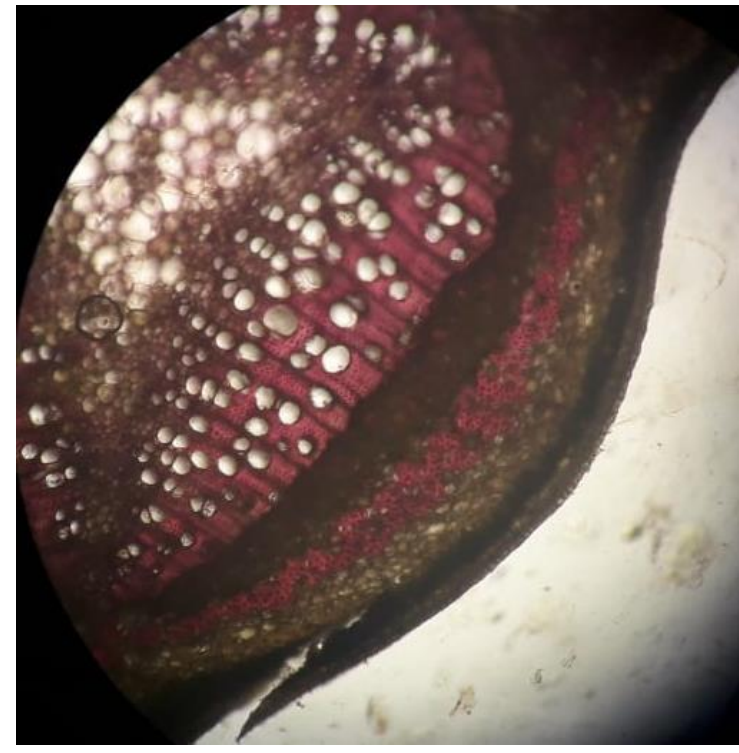

\section{Conclusões}

Devido à importância farmacêutica da andiroba, além de seus demais usos, faz-se necessária a realização de mais estudos para aprofundar as informações acerca de suas propriedades. $\mathrm{O}$ presente trabalho confirmou as propriedades nas folhas de andiroba para uso medicinal.

\section{Referências}

BOUFLEUER, N. T. Aspectos ecológicos de andiroba (Carapa guianensis Aubl., Meliaceae), como subsídios ao manejo e conservação. Dissertação (Mestrado em Ecologia e Manejo dos Recursos Naturais)- Universidade Federal do Acre. Rio Branco. 84f. 2004.

CUNHA, M. A. E. Estudo do Processo de Extração Supercrítica do resíduo sólido da semente de Andiroba. 2002. Dissertação (Mestrado em Engenharia Química) - Universidade Federal do Pará. Belém, 2002. 
SHANLEY, P.; CYMERYS, M.; GALVÃO, J. Frutíferas da mata na vida amazônica. Belém, 127p. 1998.

SILVA, B. C. Caracterização anatômica de folhas da andiroba (carapa guianensis aubl.), PARA FINS DE DEFINÇÕES DE USO POPULAR. II Congresso Internacional de Ciências Agrárias. 2017. 